\title{
Surgical Treatment of Partial Atrioventricular Septal Defect. Functional Analysis of the Mitral Valve in the Postoperative Period
}

\author{
Josué Viana Castro Neto, Paulo Chaccur, Cláudio Leo Gelape, Eliseu de Sousa Santos, Hélio Carlos Falcão, \\ Mário Issa, Antoninho Sanfins Arnoni, Flávio Sanches Almeida, Camilo Abdulmassih Neto, \\ Jarbas Jackson Dinkhuysen, Luís Carlos Bento Souza, Paulo Paredes Paulista
}

São Paulo, SP - Brazil

Objective - To study mitral valve function in the postoperative period after correction of the partial form of atrioventricular septal defect.

Methods - Fifty patients underwent surgical correction of the partial form of atrioventricular septal defect. Their mean age was 11.8 years and $62 \%$ of the patients were males. Preoperative echocardiography showed moderate and severe mitral insufficiency in $44 \%$ of the patients. The mitral valve cleft was sutured in 45 (90\%) patients (group II - GII). Echocardiographies were performed in the early postoperative period, and 6 and 12 months after hospital discharge.

Results - The patients who had some type of arrhythmia in the postoperative period had ostium primum atrial septal defect of a larger size $(2.74 \times 2.08 \mathrm{~cm})$. All 5 patients in group I(GI), who did not undergo closure of the cleft, had a competent mitral valve or mild mitral insufficiency in the preoperative period. One of these patients began to have moderate mitral insufficiency in the postoperative period. On the other hand, in GII, $88.8 \%$ and $82.2 \%$ of the patients had competent mitral valve or mild mitral insufficiency in the early and late postoperative periods, respectively.

Conclusion-Themitral valvecleft was repaired in $90 \%$ of cases. Echocardiography revealed competent mitral valve or mildmitral insufficiency in $88.8 \%$ and $82.2 \%$ of GII patients in the early and late postoperative periods, respectively.

Keywords: partial atrioventricular septal defect, surgery, mitral valve, congenital heart diseases, cardiovascular surgical procedures

Instituto Dante Pazzanese de Cardiologia and Hospital do Coração - Associação do Sanatório Sírio

Mailing address: Josué V. Castro Neto - Rua Rio Grande, 321/142 - 04018-000 São Paulo, SP, Brazil - E-mail: jven@uol.com.br

English version by Stela Maris C. e Gandour
The partial form of atrioventricular septal defect is the combination of an ostium primum atrial septal defect and a cleft in the anterior or aortic leaflet of the mitral valve.

Since the report of the first surgical repair in 1954 by Lillehei et al ${ }^{1}$, the treatment of this heart anomaly has significantly evolved. However, one of the most challenging technical characteristics for the surgeon is the relation between mitral valve deformity and the capacity to maintain it competent in the postoperative period. Other studies have shown that residual mitral insufficiency is the major cause of reoperation in these patients.

This study aimed at analyzing retrospectively the behavior of the mitral valve in the early postoperative period and up to 1 year after repair of partial atrioventricular septal defects in 50 patients who underwent surgery.

\section{Methods}

Between January 1995 and July 2000, 50 patients with partial atrioventricular septal defect underwent surgical repair at the Instituto Dante Pazzanese de Cardiologia. Their ages ranged from 2 months to 58 years (mean of 11.8 years), their weights ranged from 2.5 to $92 \mathrm{~kg}$ (mean of $27 \mathrm{~kg}$ ), and 31 $(62 \%)$ patients were males. The size of the ostium primum atrial septal defect ranged from 1.05 to $4.6 \mathrm{~cm}$ (mean of 2.30 $\mathrm{cm}$ ). Twenty-two (44\%) patients had moderate or severe mitral insufficiency in the preoperative period. All patients underwent echocardiography in the early postoperative period (within 1 month), and $90 \%$ of the patients underwent that procedure within 1 year (late follow-up). Preoperative cardiac catheterization was performed in $88 \%$ of the patients, showing pulmonary hypertension (mean $\geq 25 \mathrm{mmHg}$ ) in $34 \%$ of the patients.

In regard to the surgical technique, the patients were operated upon with extracorporeal circulation, moderate hypothermia $\left(28-30^{\circ} \mathrm{C}\right)$, and myocardial protection with 
blood or crystalloid cardioplegia. The mitral valve cleft was sutured with separated stitches (polypropylene thread), which were eventually anchored in pericardium.

In all patients, the ostium primum atrial septal defect was repaired with a pericardial patch; in $4(8 \%)$ patients, the coronary sinus was redirected to the left atrium, avoiding suture in the region of the conduction tissue.

Forty-seven (94\%) patients had preoperative sinus rhythm, and 6 had first-degree atrioventricular block. Of those patients with cardiac rhythm other than sinus rhythm (3), 1 had atrial fibrillation, 1 had junctional rhythm, and 1 had total atrioventricular block (fig. 1). Ostium secundum atrial septal defect was the most common associated defect (fig. 2).

Due to didactic reasons, the sample was divided into 2 groups as follows: group I(GI) - comprising 5 patients, who did not undergo closure of the mitral valve cleft (NFC); and group II(GII) - comprising 45 patients who underwent suture of the mitral valve cleft (FC). Each group was further divided into 2 subgroups as follows: subgroup comp/mild, in which the mitral valve was competent or slightly insufficient; and subgroup mod/sev, in which mitral insufficiency was moderate or severe.

The results were analyzed with the Fisher exact test and the Mann-Whitney nonparametric test with a significance of $\mathrm{p}<0.05$.

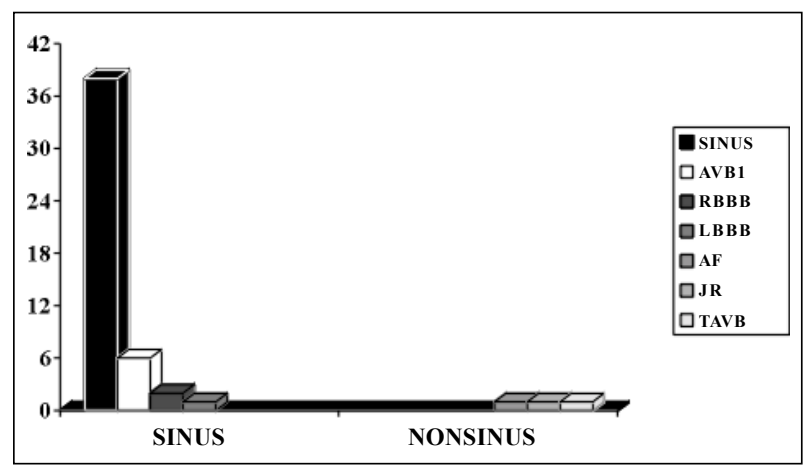

Fig. 1 -Preoperative cardiac rhythm of 50 patients with partial atrioventricular septal defect who underwent surgical treatment. Sinus rhythm $(n=47)$ and nonsinus rhythm $(n=3)$.

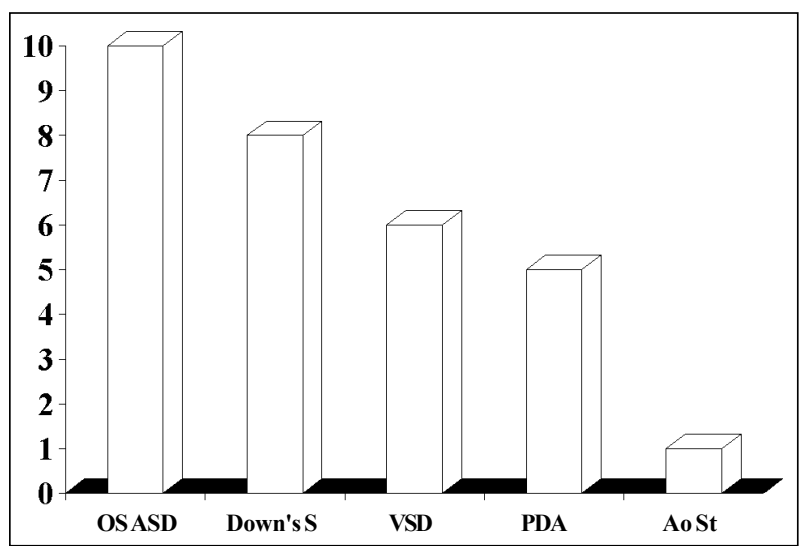

Fig. 2 - Associated defects in 50 patients with partial atrioventricular septal defect who underwent surgical treatment.

\section{Results}

No in-hospital mortality was observed. Arrhythmia was the most common postoperative complication occurring in $10(20 \%)$ patients as follows: $6(12 \%)$ patients had junctional rhythm, $3(6 \%)$ had total atrioventricular block, and 1 had supraventricular paroxysmal tachycardia. The incidence of arrhythmia was related to the size of the ostium primum atrial septal defect. Patients with arrhythmia in the postoperative period had larger ostium primum atrial septal defects than those who did not have that complication; however, the Mann-Whitney test showed no statistical significance $(\mathrm{p}=0.08)$ (fig. 3). The following complications were also found: bronchopneumonia in 3 patients, review of hemostasia due to significant bleeding in 2 patients, and cerebral stroke in 2 patients, being transitory in 1 and definite in another (fig. 4). In addition to repair of the atrial septal defect, the following defects were also fixed: ostium secundum atrial septal defect (10 patients), ventricular septal defect (6 patients) - ventricular inlet (3) and muscular (3), and patent ductus arteriosus ( 5 patients). In addition, 4 definite pacemakers were implanted, and 2 mitral valve procedures ( 1 duplication of the mitral orifice and 1 annuloplasty) and 2 tricuspid valve procedures (2 De Vega tricuspid valve annuloplasties) were performed (fig. 5).

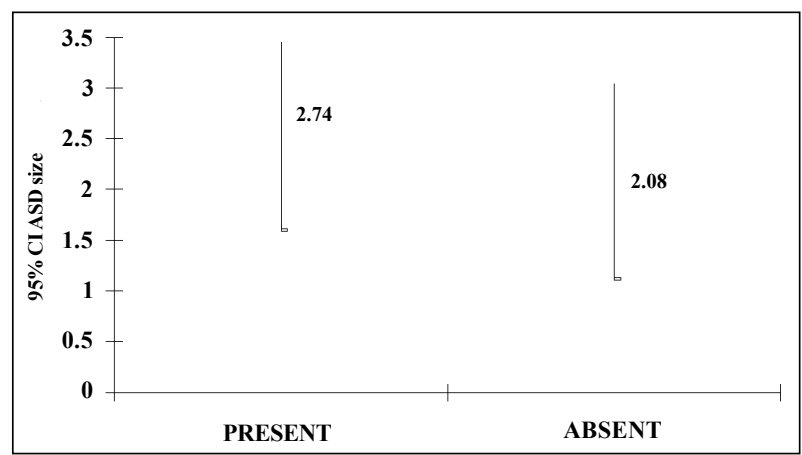

Fig. 3 - Graph correlating the size $(\mathrm{cm})$ of the ostium primum atrial septal defect and the presence or absence of arrhythmia in the early postoperative period. Using the Mann-Whitney test, patients who evolved with arrhythmia had a tendency to have larger atrial septal defect $(\mathrm{p}=0.08)$.

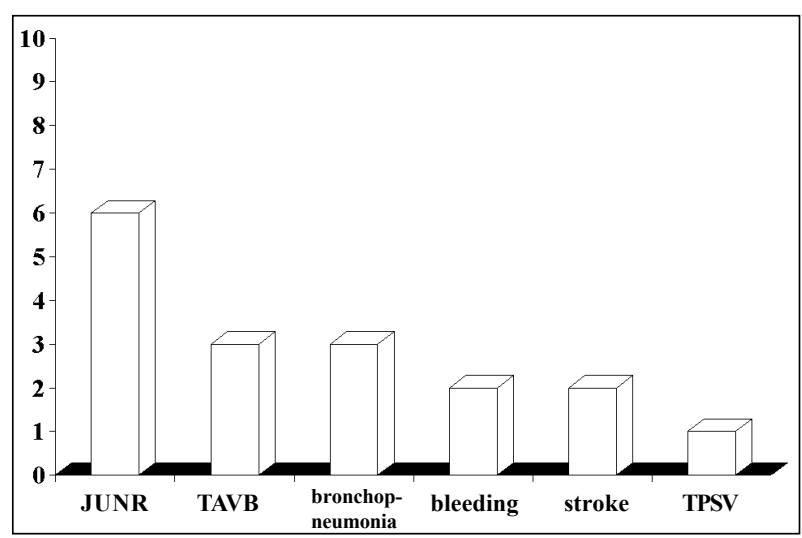

Fig. 4 - Complications in the early postoperative period of 50 patients treated for partial atrioventricular septal defect. 


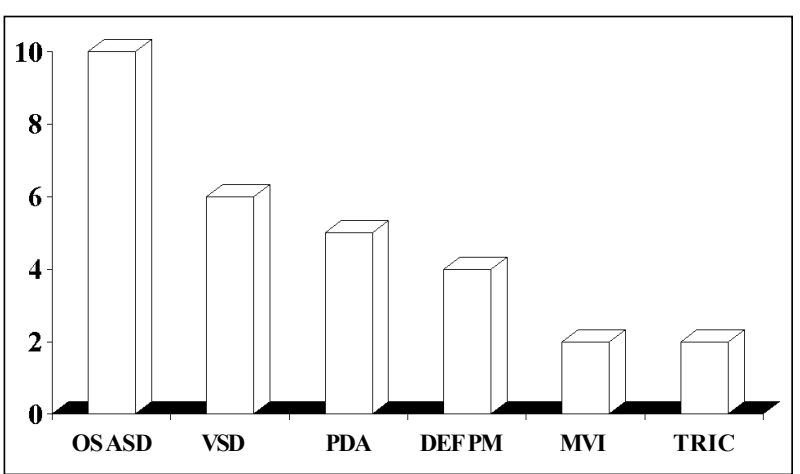

Fig. 5 - Procedures associated with surgical repair of partial atrioventricular septal defect in 50 patients.

Two patients underwent reoperation in the period of time studied. One patient showed a residual defect at the level of the pericardial suture 2 years after surgery. The repair consisted of resuture of the orifice site. Another patient, who evolved with severe mitral insufficiency 3 years after surgery, required a quadrangular resection of the posterior leaflet and annuloplasty with bovine pericardial flap.

The echocardiograms of GI patients (fig. 6), those who did not undergo closure of the mitral valve cleft (NFC) $(\mathrm{n}=5)$, showed a competent or slightly insufficient mitral valve in the preoperative period (comp/mild subgroup). In the early postoperative period, $4(80 \%)$ patients remained in the comp/mild subgroup, and 1 (20\%) patient evolved with moderate mitral insufficiency (mod/sev subgroup).

In GII (FC) ( $\mathrm{n}=45$ - fig. 7), 23 patients had competent or slightly insufficient mitral valve (comp/mild subgroup), and 22 patients had moderate or severe mitral valve insufficiency ( $\mathrm{mod} / \mathrm{sev}$ subgroup) in the preoperative period. In regard to the comp/mild subgroup, 21 (91.3\%) patients remained in this subgroup, while $2(8.7 \%)$ evolved with moderate or severe mitral insufficiency (mod/sev subgroup). Of the $\mathrm{mod} / \mathrm{sev}$ subgroup in the preoperative period $(\mathrm{n}=22), 19$ $(86.3 \%)$ patients passed to the comp/mild subgroup and 3 (13.7\%) patients remained in the mod/sev subgroup in the early postoperative period.

Of the 45 GII patients, $40(88.8 \%)$ were in the comp/ mild subgroup in the early postoperative period. Of them, 37 $(92.5 \%)$ remained in that subgroup in the postoperative period for up to 1 year, ie, $82.2 \%$ of all GII patients.

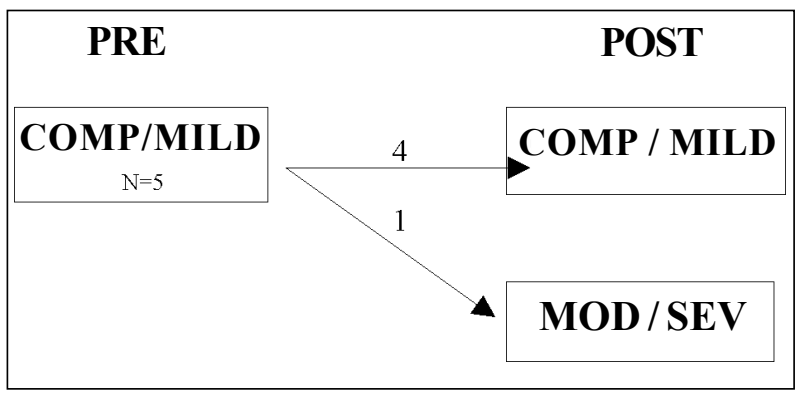

Fig. 6 - Representative sketch of the pre- and early postoperative echocardiographic assessment in GI patients (NFC) $(n=5)$.

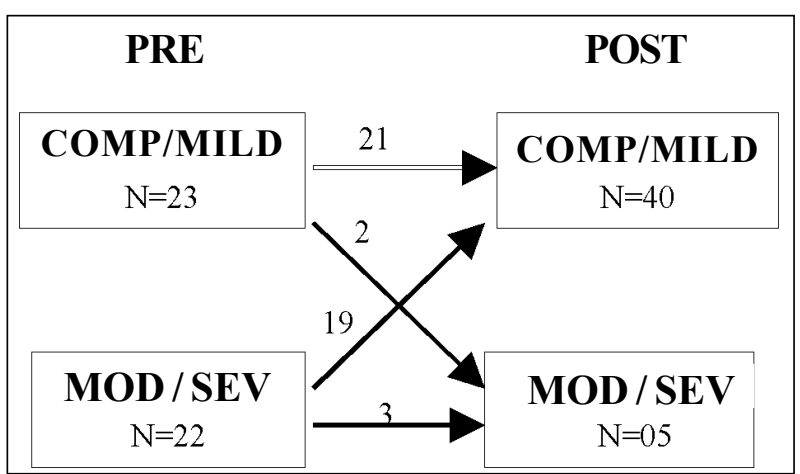

Fig. 7 - Representative sketch of the pre- and early postoperative echocardiographic assessment in GII patients (FC) $(\mathrm{n}=45)$.

\section{Discussion}

The evolution of the treatment of the partial form of atrioventricular septal defect since its first surgical repair reported by Lillehei et al ${ }^{1}$ in 1954 has been significant. Good results have been consecutively obtained, and currently this heart anomaly may be surgically treated with low morbidity and mortality ${ }^{2}$.

However, a challenging technical characteristic for the surgeon is the ability to maintain the mitral valve competent in the postoperative period. The problem of residual mitral insufficiency in the repair of the partial form of atrioventricular septal defect preceded the advent of echocardiography. At that time, surgeons used clinical and cardiac catheterization findings, and also their results in the postoperative period to assess the disease and the degree of valve impairment ${ }^{3,4}$.

Some authors ${ }^{5-8}$ have reported that this complication is one of the major causes of reoperation.

In the group of patients studied, no in-hospital mortality occurred. The most recent studies have shown mortality ranging from 0 to $3 \%$.

Another feared complication is total atrioventricular block, which was observed in $3(6 \%)$ patients in our study. Its incidence has been reported ranging from $2.7 \%$ to $6 \%{ }^{6-8}$.

Patients who evolved with a certain type of arrhythmia in the postoperative period had ostium primum atrial septal defect with a mean size of $2.74 \mathrm{~cm}$, while those with sinus rhythm had a defect with a mean size of $2.08 \mathrm{~cm}$. Even though a larger atrial septal defect was found in the patients who evolved with arrhythmia, this difference did not reach statistical significance $(\mathrm{p}=0.08)$ according to the Mann-Whitney test.

The GI sample comprised 5 patients, all of whom had competent or a slightly insufficient mitral valve in the preoperative period. In GII, however, 23 (51.1\%) patients belonged to the comp/mild subgroup, which reflects the surgeons' belief that most patients should have their mitral defects fixed. King et $\mathrm{al}^{6}$, at the Mayo Clinic, closed the mitral valve cleft in all cases, independently of the degree of mitral valve impairment. This management resulted from the observation of late mitral insufficiency in patients who had not 
undergone closure of the mitral valve cleft, thus requiring a later closure.

One GI patient and 5 GII patients evolved with moderate or severe mitral insufficiency in the postoperative period. In these cases, initial clinical follow-up was the choice. Another GII patient underwent reoperation 3 years after the initial procedure. On that occasion, the surgical finding allowed mitral valve plasty with quadrangular resection and annuloplasty with a bovine pericardial flap. This means that closure of the cleft in the anterior leaflet did not seem to play a major role in the etiology of insufficiency, because intervention in the other leaflet was necessary to fix the problem. El-Najdawi et al ${ }^{7}$ have shown an incidence of at least moderate mitral insufficiency in $18 \%$ of the patients in a very late postoperative period, and $11 \%$ of the patients underwent reoperation in up to 40 years.
It is worth emphasizing that of the 23 GII patients in the comp/mild subgroup, 21 (91.3\%) maintained that pattern in the late postoperative period. Of the 22 GII patients in the $\mathrm{mod} / \mathrm{sev}$ subgroup, $19(86.3 \%)$ evolved to the comp/mild subgroup, showing a good evolution in GII independently from the subgroup assessed.

Becker and Anderson ${ }^{9}$ have emphasized that, from the anatomical point of view, what is routinely called a mitral valve cleft in the partial atrioventricular septal defect cannot be surgically reconstituted to produce a structure similar to the aortic leaflet of the normal mitral valve.

We believe that it is not the surgeon's intention to reproduce anatomical perfection, but to minimize morbidity in the postoperative period with the best treatment available for any given disease.

\section{References}

1. Lillehei C, Cohen M, Warden H. Direct vision intracardiac correction of congenital anomalies by controlled cross circulation: results in 32 patients with ventricular septal defects, Tetralogy of Fallot, and atrioventricular communis defects. Surgery 1955; 38: 11-29.

2. Losay J, Rosenthal A, Castaneda AR, Bernhard WH, Nadas AS. Repair of atrial septal defect primum. Results, course, and prognosis. J Thorac Cardiovasc Surg 1978; 75: 248-54.

3. Griffiths SP, Ellis K, Burris JO, Bumenthal S, Bowman FO, Malm JR. Postoperative evaluation of mitral valve function in ostium primum defect with fenda mitral valve (partial form of atrioventricular canal). Circulation 1969; 40: 21-9.

4. Mcmullan MH, McGoon DC, Wallace RB, Danielson GK, Weidman WH. Surgical treatmente of partial atrioventricular canal. Arch Surg 1973; 107: 705-10.
5. Goldfaden DM, Jones M, Morrow AG. Long-term results of repair of incomplete persistent atrioventricular canal. J Thorac Cardiovasc Surg 1981; 82: 669-73.

6. King RM, Puga FJ, Danielson GK, Schaff HV, Julsrud PR, Feldt RH. Prognostic factors and surgical treatment of partial atrioventricular canal. Circulation 1986; 74(suppl I): I-42-I-46.

7. El-Najdawi EK, Driscoll DJ, Puga FJ, et al. Operation for partial atrioventricular septal defect: A forty-year review. J Thorac Cardiovasc Surg 2000; 119: 880-90.

8. Burke RP, Horvath K, Landzberg M, Hyde P, Collins JJ, Cohn LH. Long-term follow-up after surgical repair of ostium primum atrial septal defect in adults. J Am Coll Cardiol 1996; 27: 696-9.

9. Becker AE, Anderson RH. Atrioventricular septal defects: What's in a name? J Thorac Cardiovasc Surg 1982; 83: 461-9. 